\title{
CORRECTION
}

\section{Correction to: xSDL: stroboscopic differential lighting eye tracker with extended temporal support}

\author{
Frank H. Borsato ${ }^{1}$ (]) Antonio Diaz-Tula $^{2} \cdot$ Carlos H. Morimoto ${ }^{2}$
}

Published online: 22 May 2019

๑) Springer-Verlag GmbH Germany, part of Springer Nature 2019

\section{Correction to: Machine Vision and Applications https://doi.org/10.1007/s00138-019-01022-y}

Unfortunately, Fig. 9 was incorrectly published in the online version. Correct figure is updated here.

The original article has been corrected.

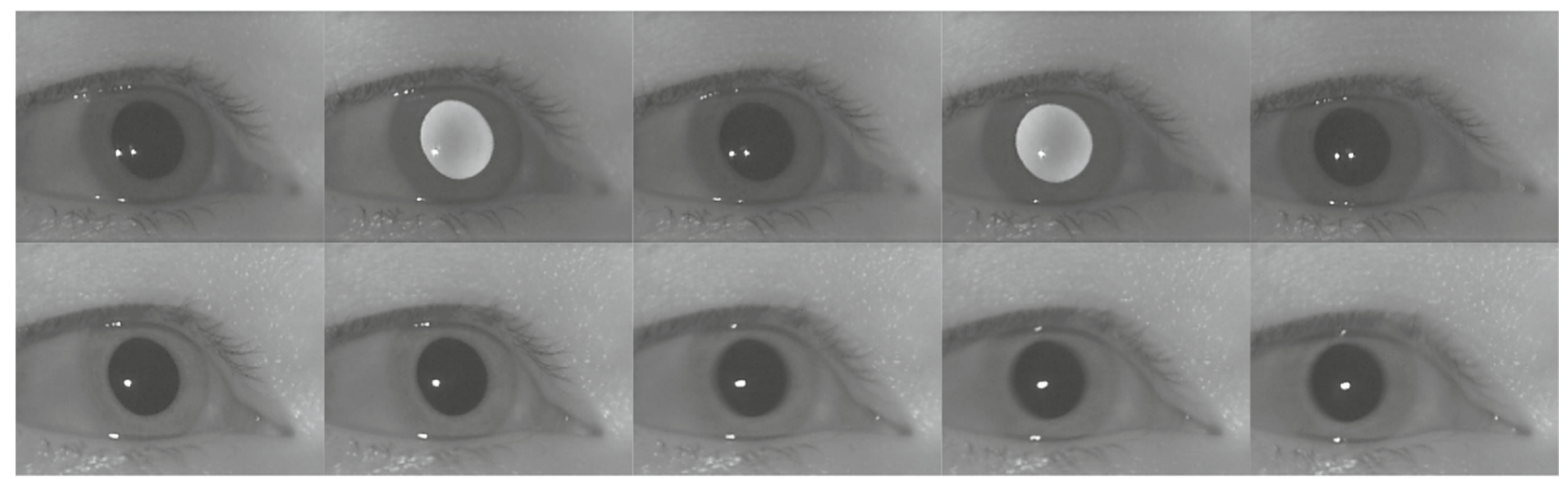

Fig. 9 Example capture of a participant with an ongoing saccade. On top, xSDL camera images and on bottom, continuous $940 \mathrm{~nm}$ illuminated images

The original article can be found online at https://doi.org/10.1007/ s00138-019-01022-y.

Frank H. Borsato

frankhelbert@utfpr.edu.br

1 Universidade Tecnológica Federal do Paraná, Via Rosalina Maria dos Santos 1233, Campo Mourão 87301-899, Brazil

2 Universidade de São Paulo, Rua do Matão 1010, São Paulo 05508-090, Brazil 